\title{
Stroke: Insights into Thromboembolism Treatment and Prevention through the Decades
}

\author{
George Ntaios ${ }^{1}$ Gregory Y. H. Lip ${ }^{2,3}$ \\ ${ }^{1}$ Department of Internal Medicine, University of Thessaly, Larissa, \\ Greece \\ 2 Liverpool Centre for Cardiovascular Science, Liverpool Heart \& Chest \\ Hospital, University of Liverpool, Liverpool, United Kingdom \\ 3 Aalborg Thrombosis Research Unit, Department of Clinical \\ Medicine, Aalborg University, Aalborg, Denmark \\ Thromb Haemost 2019;119:685-687.
}

With the availability of back issues online for Thrombosis $\mathcal{E}$ Haemostasis ever since the original first published issue in 1957 (then under the name Thrombosis et Diasthesis Haemorrhagica), we felt that stroke could be an initial special focus, given the publication on this topic in Volume 1, Issue 1 of this journal. ${ }^{1}$

Way back in 1957, the era that 'the treatment for all cerebral vascular diseases was futile' 1 and 'the physician's choice lay between masterly inactivity and skilful neglect ${ }^{2}$, was slowly giving its place to a period of progress in stroke prevention and treatment. At that time, physicians were beginning to feel optimistic that they had started climbing up the learning curve, although it was still clear that they 'did not consider present treatment entirely satisfactory. ${ }^{1}$

Let's take a hypothetical patient, Michael, in the 1950s. If only Michael could share his optimism this evening. For the last 2 hours, he was lying on a bed in the emergency department of the hospital waiting for a physician to examine him and help him talk and move his right leg and hand again. It was easy for him to guess that he was having a "brain attack"many of his friends had suffered something similar, and many of them did not make it through. Next day, although dizzy, Michael could listen to the doctor talking to his daughter:

- 'We took some fluid from his spinal cord for examination and we tend to conclude that this is probably a nonhaemorrhagic infarction (1). We don't really know why it happened, for most of our patients we don't. ${ }^{1}$ I won't fool you, the management of this entity is discouragingly inadequate. $^{3}$ We tried all our weapons: we blocked his stellate ganglion to increase the collateral vessels around the dead zone, ${ }^{3}$ we administered intravenous procaine $e^{4}$ and histamine $^{5}$, carbon dioxide $e^{2}$, nicotine and whiskey, ${ }^{3}$ ephedrine and ritalin ${ }^{6}$, cortisol, ${ }^{6}$ we tried everything... I am sorry, no improvement'.

\section{received}

March 5, 2019

accepted

March 11, 2019

\author{
Address for correspondence George Ntaios, MD, MSc, PhD, \\ Department of Internal Medicine, University of Thessaly, Larissa, \\ Greece (e-mail: gntaios@med.uth.gr).
}

- 'Will you do an arteriogram to my father, doctor?', she asked.

- 'Of course not, there are no indications for this, ${ }^{6}$ it is only experimental', the doctor responded decisively.

- 'Will you treat him with anticoagulants, doctor?', she asked again looking desperately for a glimpse of hope.

- 'No', he said avoiding looking her in the eyes. 'We are rather reluctant with this form of treatment. In our own hospital we have been impressed by the dangers of using anticoagulants in the severely hypertensive patient and by the incidence of haemorrhagic problems that occur when long-term anticoagulation is undertaken. It certainly should not be considered a benign procedure but rather one which presents definite risks, ${ }^{6}$

The doctor proved to be right: Michael did not make it through, and he never made it to see Helena, his fourth grandchild, to be born a few weeks later.

\section{Time Passes, and the Approach to Stroke Care Changes with Time}

Helena never met her grandfather, but her parents told her the story of his last weeks, on several occasions. On her 60th birthday, the last weeks of her grandfather suddenly came back to her in a flash when she fell down unable to move her left hand and leg. 'It's a stroke', she said, but her son could not understand a single word from what she was trying to say. He immediately called an ambulance, which arrived within just 10 minutes. 'This doesn't look like a usual ambulance', he mumbled. 'Yes', the physician of the ambulance responded, 'it has a computed tomography (CT) scanner and your mother will have a CT scan on her way to the hospital, and perhaps, she may even start receiving a drug to dissolve the

(c) 2019 Georg Thieme Verlag KG Stuttgart · New York
DOI https://doi.org/ 10.1055/s-0039-1685454. ISSN 0340-6245. 
clot which blocked her arteries, before she reaches the hospital'. 7,8

Indeed, Helena started receiving alteplase while being rushed to the hospital. ${ }^{7,8}$ When she reached the hospital, she was taken directly into the angio suite and a wire was used to retrieve the clot which was blocking her artery. ${ }^{9,10}$ Next day, she was walking and smiling again.

- 'So, what happened to me, doctor?', she asked.

- 'We found that you have an arrhythmia that you were not aware of, it's called atrial fibrillation. ${ }^{11}$ This formed a thrombus in your heart, which then left your heart and blocked one of the large arteries in your head. ${ }^{12}$ You were lucky..., she heard him saying. 'You will start a medication to prevent this clot formation again, and we know that it can help you. ${ }^{13-16}$ It's easy to take and you should not stop it. ${ }^{17}$ If you follow my instructions, there is a very good chance that this will not happen again'. ${ }^{18-20}$

Next day, Helena was back home again enjoying her time with Anastasia, her granddaughter-how blessed she felt that she could teach her again how to play the piano.

\section{Historical Perspectives}

Looking back from 2017 to 1957 and from Helena to Michael through the prism of our current knowledge, one can only smile with enthusiasm and excitement of the huge progress which took place in thromboembolic stroke treatment and prevention. What was once a lost case, is now a treatable and preventable condition. Stroke research, directed toward all aspects of stroke medicine like primary and secondary prevention, acute treatment and rehabilitation, is continuously expanding the borders of our knowledge and our ability to help our patients. Many physicians from different specialty backgrounds are now actively engaged to stroke medicine helping more and more patients prevent their stroke or receive specialized stroke care and rehabilitation if it occurs. The focus on atrial fibrillation and stoke prevention has moved towards a simple integrated or holistic approach ('easy as ABC': 'A' Avoid stroke with Anticoagulation; 'B' Better symptom management; ' $C$ ' Cardiovascular and comorbidity risk management), which has been associated with much improved clinical outcomes. ${ }^{21-23}$

It is likely that in 60 years from now, the stroke physicians of the future will be looking back at us smiling again with enthusiasm and excitement with the progress which will have occurred in the meantime. It is also likely that in 60 years from now, our current standards of stroke prevention and treatment will prove to be absolutely outdated, and stroke will have become a rather infrequent and easily treatable condition. We certainly hope so.

\section{Conflict of Interest}

Dr. Lip: Consultant for Bayer/Janssen, BMS/Pfizer, Medtronic, Boehringer Ingelheim, Novartis, Verseon and Daiichi-Sankyo. Speaker for Bayer, BMS/Pfizer, Medtronic, Boehringer Ingelheim and Daiichi-Sankyo. No fees was directly received personally. Dr. Ntaios: Speaker fees from
Sanofi, Boehringer-Ingelheim, Galenica, Elpen, BMS/Pfizer and Bayer; is an advisory board member for Boehringer Ingelheim. No fees was directly received personally.

\section{References}

1 Wright IS. The challenge of cerebral vascular diseases. Thromb Diath Haemorrh 1957;1(01):26-36

2 Wolf P. TREATMENT of a stroke. Lancet 1959;1(7067):293-294

3 Aird RB, Skillicorn SA. The treatment of cerebrovascular accident. Med Clin North Am 1956;40(05):1355-1368

4 Nielsen JM. Management of cerebral vascular accidents. Ann Intern Med 1953;39(04):717-722

5 Furmanski AR. Histamine therapy in acute ischemia of the brain; a report of fifty new cases. AMA Arch Neurol Psychiatry 1953;69 (01):104-117

6 Tyler HR. Modern concepts of the pathogenesis, diagnosis and treatment of cerebrovascular accidents. Med Clin North Am 1960; 44:1215-1236

7 Ebinger M, Winter B, Wendt M, et al; STEMO Consortium. Effect of the use of ambulance-based thrombolysis on time to thrombolysis in acute ischemic stroke: a randomized clinical trial. JAMA 2014;311(16):1622-1631

8 Walter S, Kostpopoulos P, Haass A, et al. Bringing the hospital to the patient: first treatment of stroke patients at the emergency site. PLoS One 2010;5(10):e13758

9 Psychogios MN, Behme D, Schregel K, et al. One-stop management of acute stroke patients: minimizing door-to-reperfusion times. Stroke 2017;48(11):3152-3155

10 Papanagiotou P, Ntaios G. Endovascular thrombectomy in acute ischemic stroke. Circ Cardiovasc Interv 2018;11(01):e005362

11 Lip GYH, Freedman B, De Caterina R, Potpara TS. Stroke prevention in atrial fibrillation: Past, present and future. Thromb Haemost 2017;117(07):1230-1239

12 Ntaios G, Hart RG. Embolic stroke. Circulation 2017;136(25): 2403-2405

13 Borre ED, Goode A, Raitz G, et al. Predicting thromboembolic and bleeding event risk in patients with non-valvular atrial fibrillation: a systematic review. Thromb Haemost 2018;118(12): 2171-2187

14 Diener HC, Ntaios G, O'Donnell M, Easton JD. Non-vitamin-K oral anticoagulants (NOACs) for the prevention of secondary stroke. Expert Opin Pharmacother 2018;19(14):1597-1602

15 Ntaios G, Papavasileiou V, Makaritsis K, Vemmos K, Michel P, Lip GYH. Real-world setting comparison of nonvitamin-K antagonist oral anticoagulants versus vitamin-K antagonists for stroke prevention in atrial fibrillation: a systematic review and metaanalysis. Stroke 2017;48(09):2494-2503

16 Proietti M, Mujovic N, Potpara TS. Optimizing stroke and bleeding risk assessment in patients with atrial fibrillation: a balance of evidence, practicality and precision. Thromb Haemost 2018;118 (12):2014-2017

17 Loewen PS, Ji AT, Kapanen A, McClean A. Patient values and preferences for antithrombotic therapy in atrial fibrillation. A narrative systematic review. Thromb Haemost 2017;117(06): 1007-1022

18 Ntaios G, Papavasileiou V, Diener HC, Makaritsis K, Michel P. Nonvitamin-K-antagonist oral anticoagulants versus warfarin in patients with atrial fibrillation and previous stroke or transient ischemic attack: an updated systematic review and meta-analysis of randomized controlled trials. Int J Stroke 2017;12(06):589-596

19 Rivera-Caravaca JM, Roldán V, Esteve-Pastor MA, et al. Cessation of oral anticoagulation is an important risk factor for stroke and mortality in atrial fibrillation patients. Thromb Haemost 2017; 117(07):1448-1454 
20 Hohnloser SH, Basic E, Hohmann C, Nabauer M. Effectiveness and safety of non-vitamin $\mathrm{K}$ oral anticoagulants in comparison to phenprocoumon: data from 61,000 patients with atrial fibrillation. Thromb Haemost 2018;118(03):526-538

21 Lip GYH. The ABC pathway: an integrated approach to improve AF management. Nat Rev Cardiol 2017;14(11):627-628

22 Pastori D, Pignatelli P, Menichelli D, Violi F, Lip GYH. Integrated care management of patients with atrial fibrillation and risk of cardiovascular events: the $\mathrm{ABC}$ (Atrial fibrillation Better Care) pathway in the ATHERO-AF study cohort. Mayo Clin Proc 2018: S0025-6196(18)30891-7

23 Proietti M, Romiti GF, Olshansky B, Lane DA, Lip GYH. Improved outcomes by integrated care of anticoagulated patients with atrial fibrillation using the simple ABC (Atrial Fibrillation Better Care) pathway. Am J Med 2018;131(11):1359-1366 